\title{
Single Phase D-Q Theory Based Control of DER Inverters for Power Quality Improvement
}

\author{
Lavina Shilpa Stanly ${ }^{\mathrm{a}}$, Anu P, Divya R, Dr. Manjula G Nair \\ Department of Electrical and Electronics, Amrita Vishwa Vidyapeetham, Amritapuri, India \\ alavinashilpa@gmail.com
}

\begin{abstract}
This paper presents a controller for DER inverters in the distribution side to act as shunt active filters and mitigate the power quality issues in the grid without the installation of additional FACTS devices. The inverter is able to inject the real power available at the DC link from renewable energy resource as well as perform power factor correction, harmonic elimination and balancing of the loads connected to the system at the coupling point. MATLAB/SIMULINK model of the system is developed and performance of the controller is tested and validated under varying irradiance and load conditions.
\end{abstract}

Keywords-distributed generation; single phase D-Q theory; power quality; shunt active filter

\section{INTRODUCTION}

Renewable energy based Distributed Generation (DG) systems are increasing widely, of which solar photovoltaic which is clean, inexhaustable and environmental friendly is a sustainable alternate to the conventional sources of energy. The price of the PV modules was in the past a major contribution to the cost of PV systems, but grid connection saves the cost of battery. Moreover, the worldwide government policies aimed at increasing the deployment of these systems makes Solar Photovoltaic a promising energy source for the future.

In the power system various domestic and industrial loads create power quality issues. These loads results in low power factor, creates harmonics and system unbalance. Various Flexible AC Transmission Systems (FACTS) devices like passive or active filters are used for mitigating these drawbacks [1]. When compared to the bulkier and fixed passive type, active filters are of more research interest. A cost effective method of using Distributed Energy resource (DER) inverters, preferably of Solar Photovoltaic system to act as filters for three phase loads have been developed [2], [3]. Since in the distribution side were most of the loads are single phase in nature, usually single phase inverters act as shunt active filters. Thus each phase is in need of separate inverter and its control. If the 3Ф DER inverter of the DG system can be made to operate as active filter for the single phase loads at the DG side the cost of using independent filter for each phase can be saved.

In this paper the grid connected distributed generation system is controlled to act as three phase shunt active filter. The three phase interfacing inverter of the DG system is controlled using single phase D-Q frame theory to feed the active power from PV and improve the power quality of the distribution side due to various single phase linear/nonlinear loads.

\section{SYSTEM DESCRIPTION}

The block diagram of a grid interfaced Distributed generating unit is shown in Fig 1. The system consists of solar PV string, inverter and interfacing inductors. The PV string consists of series and parallel combinations of PV modules to obtain the desired power rating. The system is interfaced to the three phase grid. The loads connected at the coupling point are the local loads for the DG system and may include single phase linear and non-linear loads. The four leg three phase inverter with split capacitor as fourth leg acts as filter and provides real power injection and compensation for the local loads. 


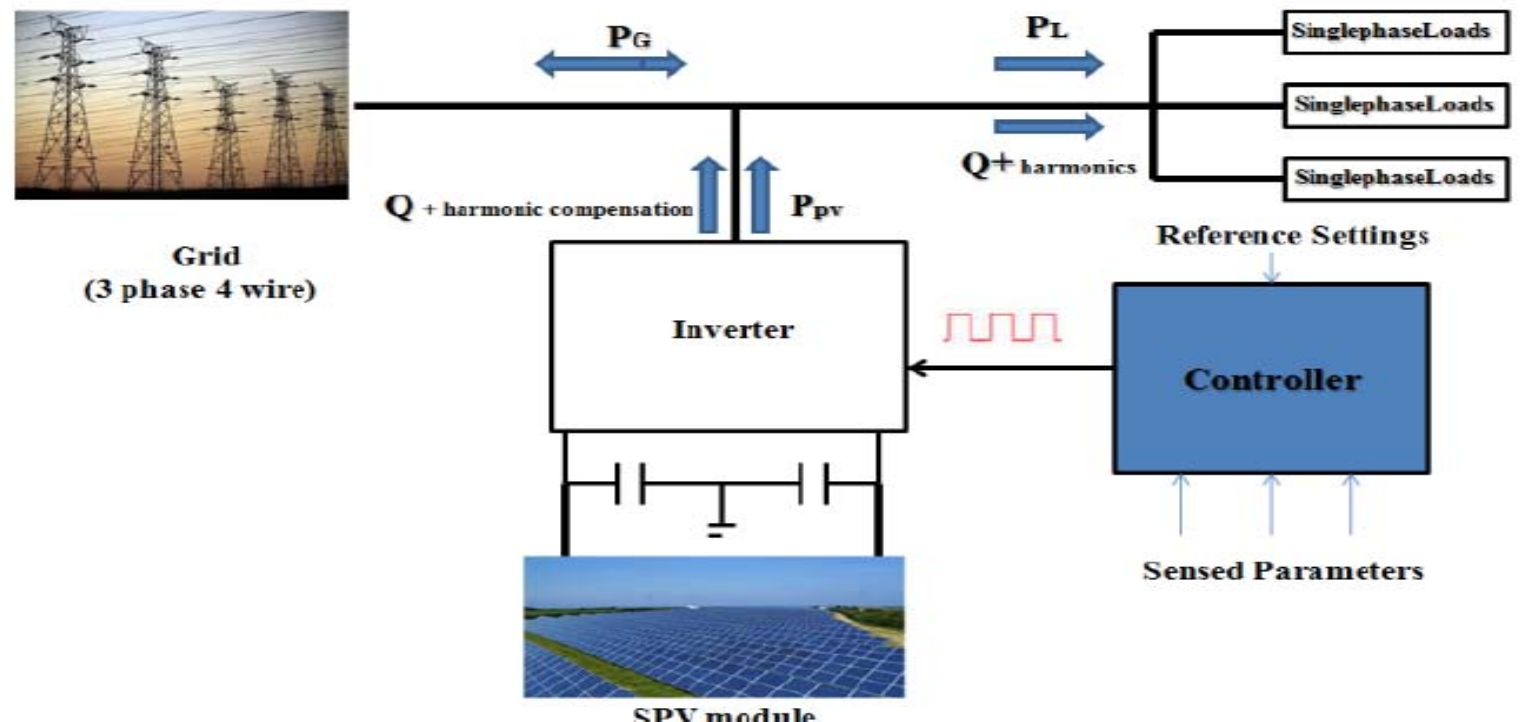

Figure 1. Block diagram of grid connected PV system

\section{CONTROL Algorithm}

The pulses for controlling the VSI is generated by PWM technique based on the reference source currents obtained using single phase D-Q frame theory based algorithm [4]. The block diagram of the control is shown in Fig 2. The single phase signal is transformed to a two phase signal and then converted to rotating frame using the following relationship.

$$
\left[\begin{array}{l}
x_{D} \\
x_{Q}
\end{array}\right]=\left[\begin{array}{cc}
\cos \theta & \sin \theta \\
-\sin \theta & \cos \theta
\end{array}\right]\left[\begin{array}{l}
x_{\alpha} \\
x_{\beta}
\end{array}\right]
$$

An easy way of generating the orthogonal system in a single-phase structure is using a transport delay block, which is responsible for introducing a phase shift of 90 degrees with respect to the fundamental frequency of the reference signals [5].

Assuming a balanced three phase source,

$$
\left.\begin{array}{l}
v_{s a}=V_{p} \operatorname{Sin} \omega t \\
v_{s b}=V_{p} \operatorname{Sin}(\omega t-120) \\
v_{s b}=V_{p} \operatorname{Sin}(\omega t+120)
\end{array}\right\}
$$

The amplitude of phase voltage is estimated as [6],

$$
V_{p}=\sqrt{\frac{2\left(v_{s a}{ }^{2}+v_{s b}{ }^{2}+v_{s c}{ }^{2}\right)}{3}}
$$

Where $v_{s a}, v_{s b}, v_{s c}$ are the instantaneous phase voltages.

Using the amplitude of phase voltages, the unit in-phase components of phase voltages are calculated as,

$$
U_{a}=\frac{v_{s a}}{V_{p}}, U_{b}=\frac{V_{s b}}{V_{p}}, U_{c}=\frac{V_{s c}}{V_{p}}
$$




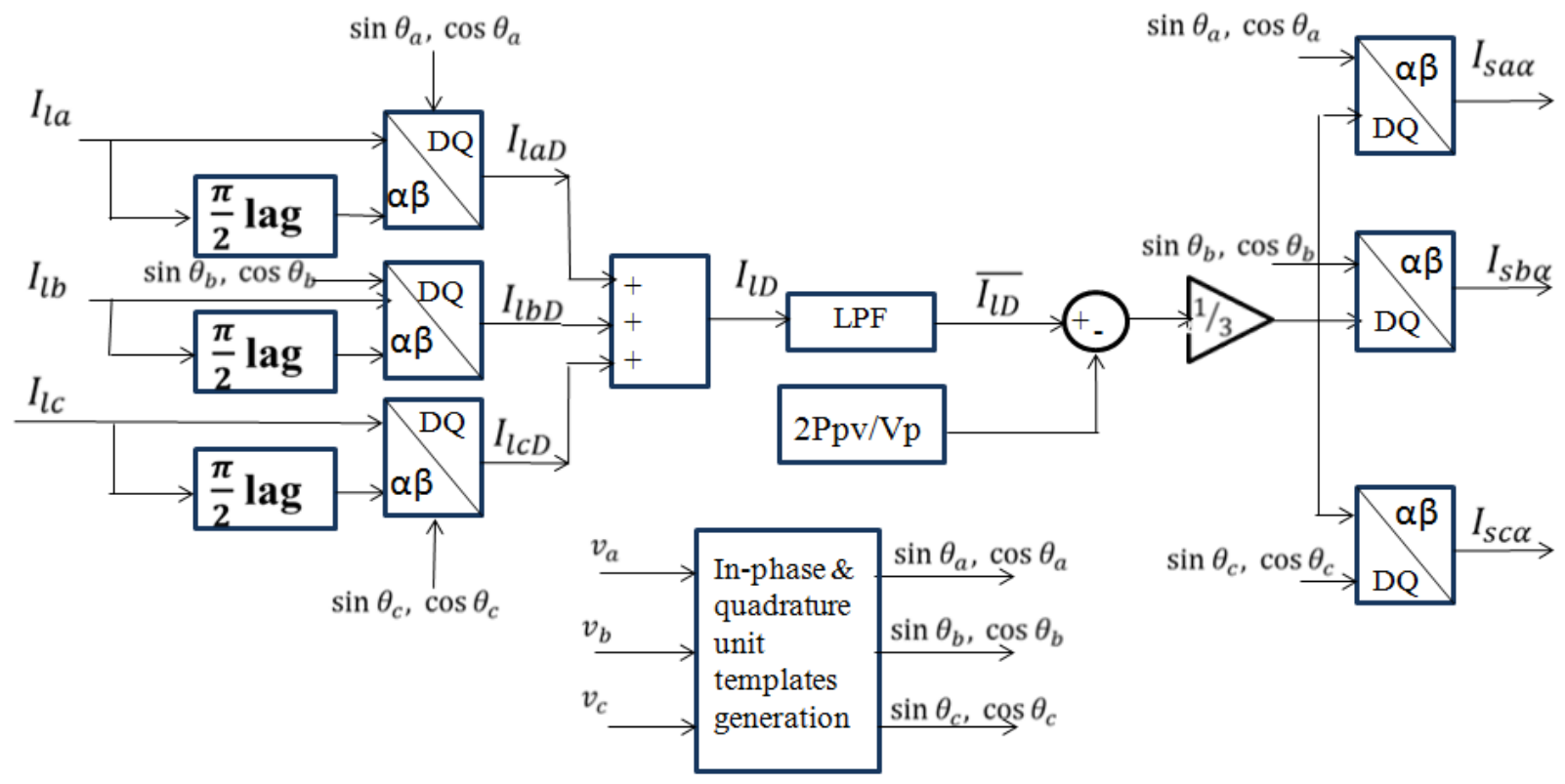

Figure 2. Block diagram of controller

The voltage and current of each phase are transformed into stationary $\alpha-\beta$ frame, and then the source voltages in stationary $\alpha-\beta$ frame are represented as

$$
\left.\begin{array}{c}
v_{a \alpha}=U_{a}, v_{b \alpha}=U_{b}, v_{c \alpha}=U_{c} \\
v_{a \beta}=U_{a}\left(t-\frac{T}{4}\right) \\
v_{b \beta}=U_{b}\left(t-\frac{T}{4}\right) \\
v_{c \beta}=U_{c}\left(t-\frac{T}{4}\right)
\end{array}\right\}
$$

Similarly the load currents in stationary $\alpha-\beta$ frame are also computed.

The load currents (iLa, iLb, iLc) are sensed and transformed into stationary $\alpha-\beta$ frame using a phase shifter. The direct axis components corresponding to load current in each phase is obtained by transforming the signals from $\alpha-\beta$ frame to synchronously rotating D-Q frame. The direct axis component of phase $\mathrm{A}$ is obtained by the following relationship

$$
\left[\begin{array}{l}
I_{l a D} \\
I_{l a Q}
\end{array}\right]=\left[\begin{array}{cc}
\cos \theta_{a} & \sin \theta_{a} \\
-\sin \theta_{a} & \cos \theta_{a}
\end{array}\right]\left[\begin{array}{c}
I_{l a \alpha} \\
I_{l a \beta}
\end{array}\right]
$$

Where $\cos \theta_{a}$ and $\sin \theta_{a}$ are calculated using the relations

$$
\left[\begin{array}{c}
\sin \theta_{a} \\
\cos \theta_{a}
\end{array}\right]=\frac{1}{\sqrt{v_{a \alpha}^{2}+v_{a \beta}^{2}}}\left[\begin{array}{c}
v_{a \alpha} \\
v_{a \beta}
\end{array}\right]
$$

Similarly D - Q components of the load currents in phases $\mathrm{B}$ and $\mathrm{C}$ can be calculated.

The equivalent D-axis component of the total load is obtained by adding the D-axis components of the three phases together.

$$
I_{l D}=I_{l a D}+I_{l b D}+I_{l c D}
$$

The source current should contain only the active component of load current for maintaining the grid quality. Therefore for balanced sinusoidal source currents, the reference source currents generated for controlling the active filter will be the average of the active component of load currents for each phase. Since the energy from DG is available at the DC link of the active filter, the reference source currents will be reduced by a value of current equivalent to the PV power at each phase.

The instantaneous equivalent current at the grid side due to $\mathrm{PV}$ is obtained by equating the dc side and ac side power at the input and output of the inverter. 


$$
\left.\begin{array}{c}
3 V_{r m s} I_{r m s}=V_{p v} I_{p v} \\
3 \frac{V_{p}}{\sqrt{2}} \frac{I_{p}}{\sqrt{2}}=P_{p v} \\
3 I_{p}=\frac{2 P_{p v}}{V_{p}}
\end{array}\right\}
$$

The net active component of the grid current,

$$
I_{\text {sref }}=\frac{I_{l D}-3 I_{p}}{3}
$$

For obtaining equal reference current in each phase the resulting current is divided by three and converted back in to the actual component using the relations given in equation 11 .

$$
\left.\begin{array}{l}
i_{\text {saref }}=I_{\text {sref }} \cos \theta_{a} \\
i_{\text {sbref }}=I_{\text {sref }} \cos \theta_{b} \\
i_{\text {scref }}=I_{\text {sref }} \cos \theta_{c}
\end{array}\right\}
$$

The reference and actual values of source currents are compared and the error is given to PWM generator for generating the control pulses for switching the inverter.

\section{SimUlation RESUlTS AND DISCUSSION}

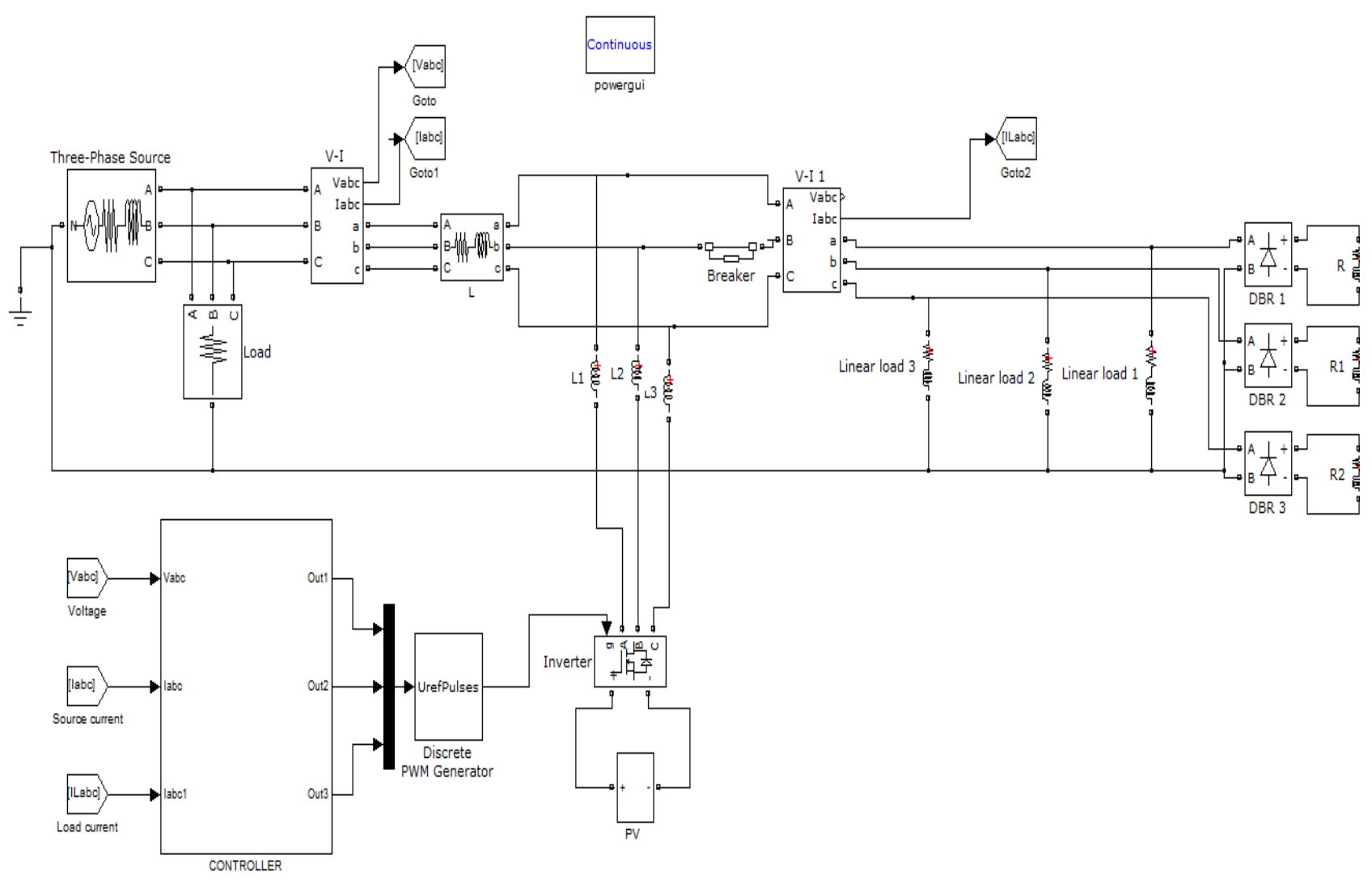

Figure 3. Simulink diagram of the test circuit

The performance of the control is tested in MATLAB/SIMULINK. The simulink model of the system developed for testing is shown in Fig 3 . It consists of a $415 \mathrm{~V}$, $50 \mathrm{~Hz}$ three phase four wire source with single phase loads. A $\mathrm{dc}$ source at the DC link of the inverter provides the real power support equivalent to PV for the local linear/nonlinear loads at PCC. The inverter feeds the real power into grid and performs active filtering under varying PV power and changing load conditions. 
TABLE I. SYSTEM SPECIFICATIONS FOR SIMULATION

\begin{tabular}{|c|c|}
\hline Grid & $415 \mathrm{~V}, 50 \mathrm{~Hz}, 3$ phase 4wire \\
\hline Single phase Linear Load & \multicolumn{2}{|c|}{$1 \mathrm{~kW}, 0.8 \mathrm{pf}$} \\
\hline $\begin{array}{c}\text { Single phase Non- Linear } \\
\text { Load }\end{array}$ & \multicolumn{2}{|c|}{$750 \mathrm{~W}$} \\
\hline PV power Variations & $\begin{array}{l}\text { 1. } 10 \mathrm{~kW} \\
\text { Zero }\end{array}$ \\
\hline Ripple Inductor & $2.5 \mathrm{mH}$ \\
\hline
\end{tabular}

Fig 4 shows the voltage and current waveforms. The waveforms clearly depict the performance of the system. Fig 5 shows the variations in PV power, load power and power at source side. It can be seen that initially from time $t=0$ to $\mathrm{t}=0.2 \mathrm{~s}$ the single phase loads are balanced, and PV power of $10 \mathrm{~kW}$ is used to feed these loads. The extra power available after feeding the local loads is fed to the grid and used by other loads at grid side. At $\mathrm{t}=0.2 \mathrm{~s}$ the load in the $\mathrm{B}$ phase is cut off by opening the circuit breaker to bring unbalance. With the PV power remaining constant the power fed to grid increases due to decrease in load. At $\mathrm{t}=0.4 \mathrm{~s}$ the PV power is reduced to zero.The total load power required is taken from the grid. At $\mathrm{t}=0.6 \mathrm{~s}$ load is introduced back in phase $\mathrm{B}$ and system is balanced. During this period since the PV power is zero, the power taken from the grid increases due to increase in power demanded by load. The inverter provides reactive power compensation, harmonic elimination and load balancing under different test conditions and maintains the grid side current sinusoidal and in phase with the source voltage.

The enlarged view of the inverter currents at different phases under different test conditions is shown in Fig 6. The inverter current contains more of real part when PV power is available from $t=0 \mathrm{~s}$ to $\mathrm{t}=2 \mathrm{~s}$. When the $\mathrm{PV}$ power is zero after $\mathrm{t}=0.2 \mathrm{~s}$, the inverter contains only the compensating current. The current at phase B is pure sine wave when the load at $\mathrm{B}$ phase is zero to maintain balanced sinusoidal currents at the grid side. Fig 7 is the enlarged view of Phase A voltage and current. Unity power factor is maintained under all test conditions

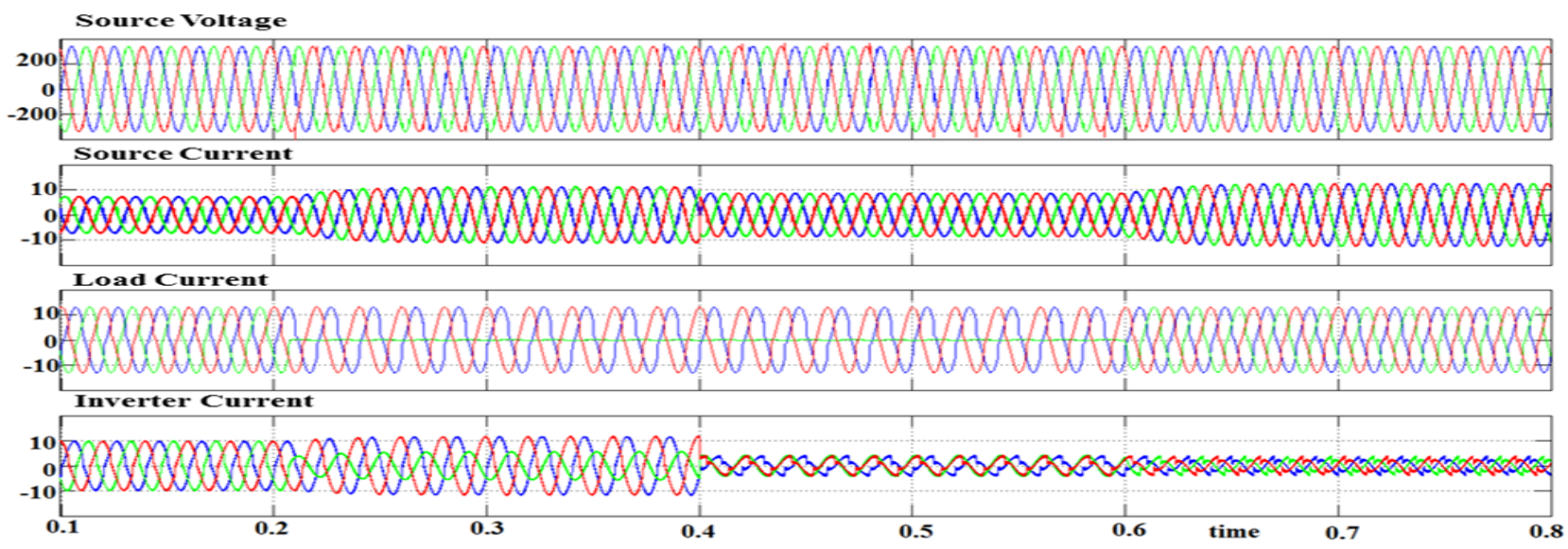

Figure 4. Waveforms of voltage and currents

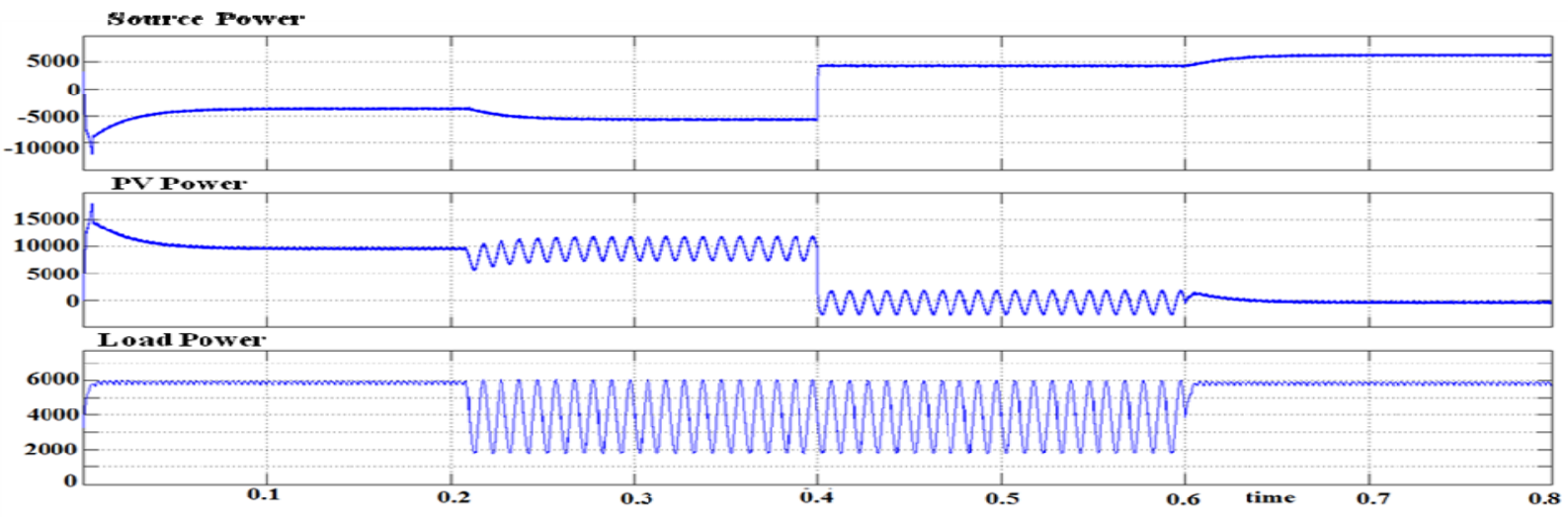

Figure 5. Waveforms showing power flow 


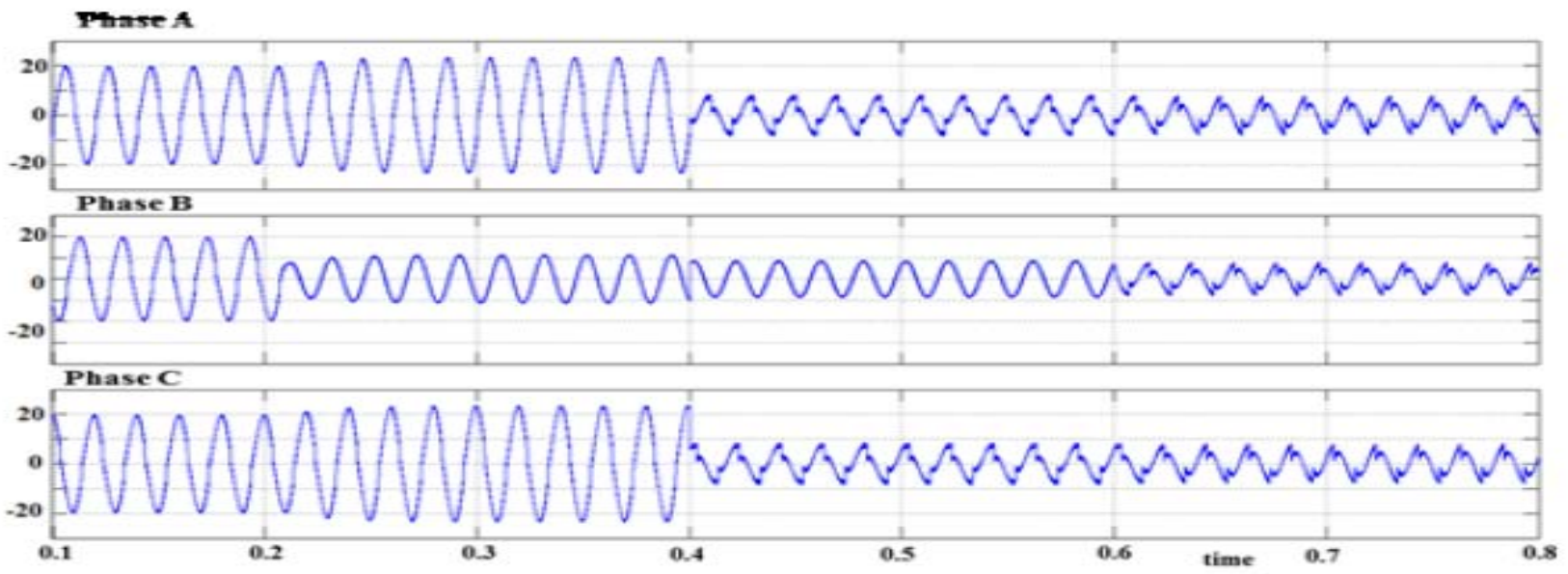

Figure 6. Enlarged view of the inverter currents

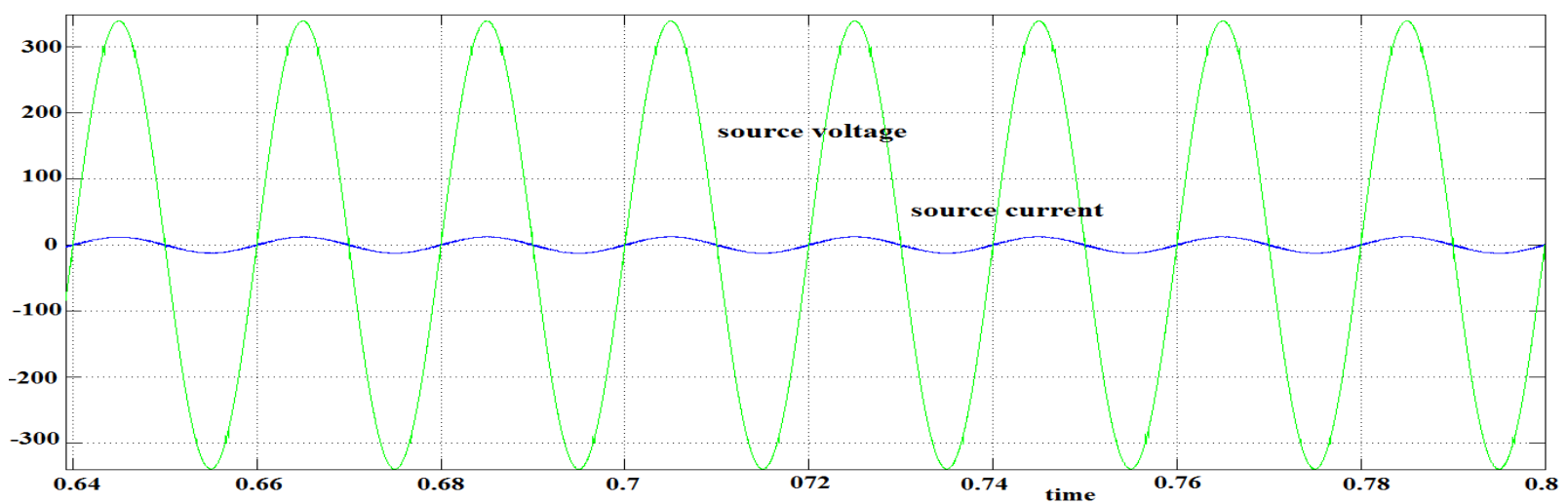

Figure 7. Enlarged view of phase A voltage and current

Results of the FFT analysis of load and source currents are shown in Fig 8. The THD of load current is $12.61 \%$ whereas the source side THD is $4.80 \%$ and within the limits.
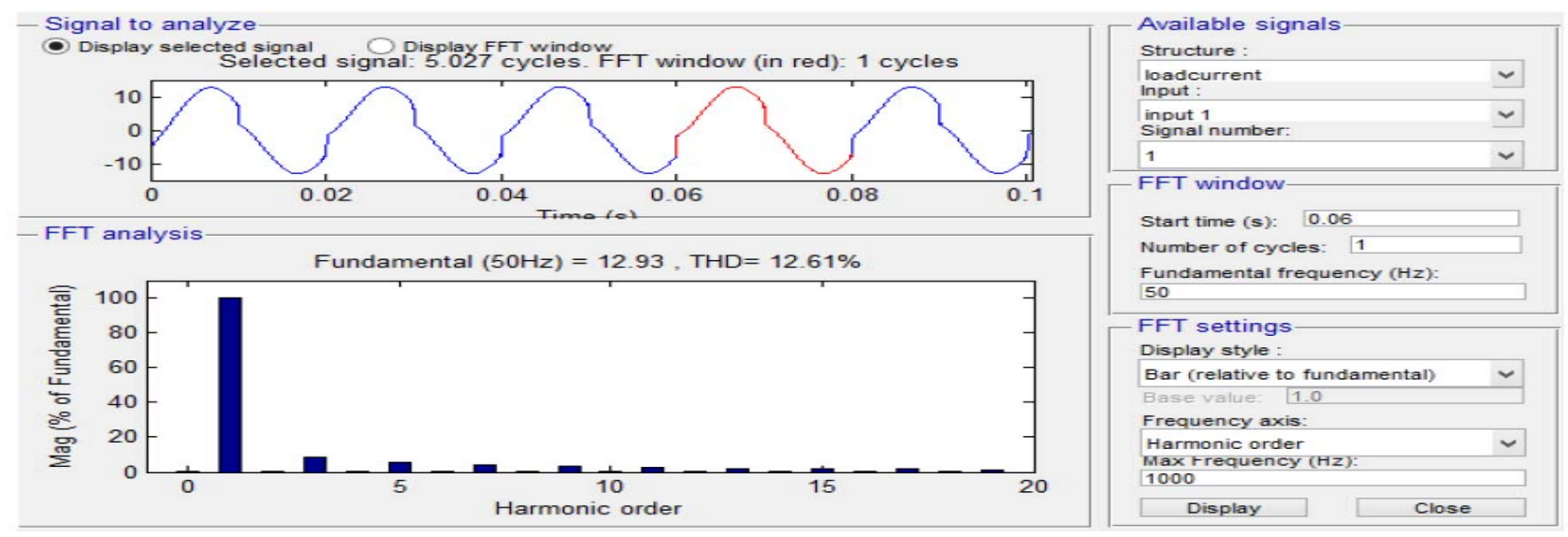

(a) 


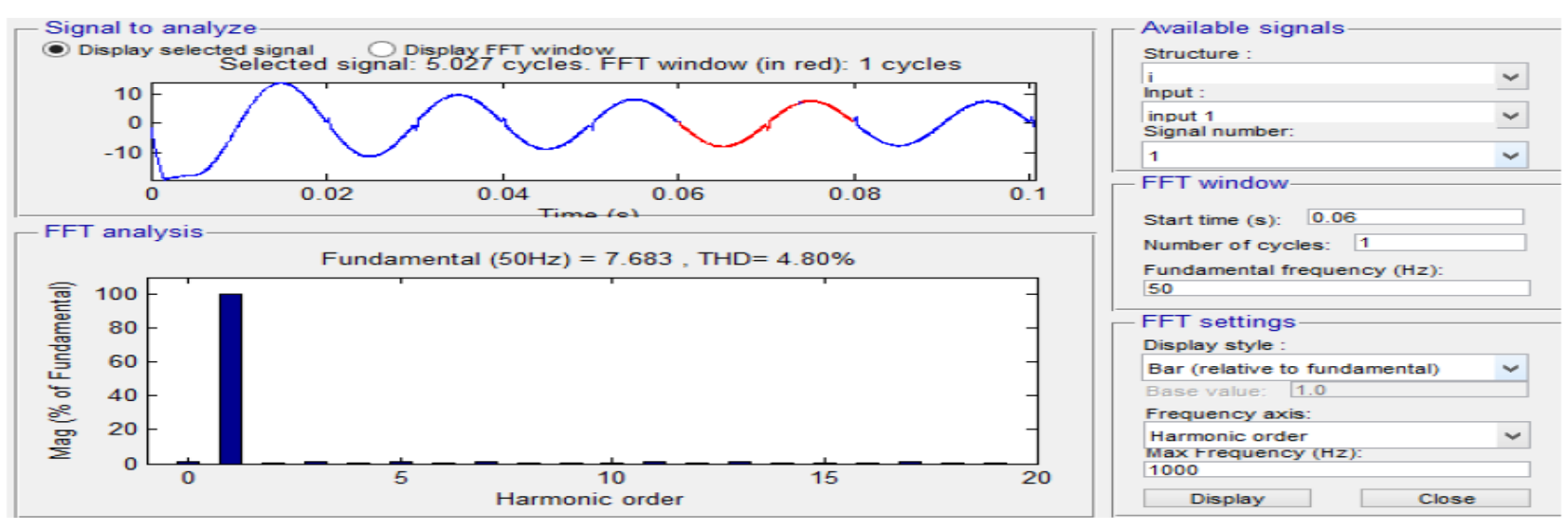

(b)

Figure 8. (a) THD of load current (b) THD of source current

\section{CONCLUSION}

The performance of DG system to operate as active filter is demonstrated in this paper. The inverter of the system compensates the various power quality issues on the grid side due to loads at the coupling point like low power factor, harmonics, and unbalance. The system when tested under different load and PV power conditions shows satisfactory results maintaining balanced sinusoidal source currents inphase with the system voltage. Maximum power point tracking of the distributed resource, wind/solar can be done by modifying the controller to make the system more efficient and suitable for a smart grid environment.

\section{REFERENCES}

[1] H.L Jou, "Performance Comparison of Three phase Active powerFilter algorithms" IEEE proceedings 1995.

[2] A. K. Verma, B. Singh, and D. T. Sahani, "Grid interfaced solar photovoltaic power generating system with power quality improvement at AC mains," presented at the IEEE 3rd Int. Conf. Sustainable Energy Technol.,Kathmandu, Nepal, Oct. 2012.

[3] Bhim Singh, Fellow, IEEE, Chinmay Jain, Member, IEEE, and Sagar Goel, Student Member, IEEE "ILST Control Algorithm of SingleStage Dual Purpose Grid Connected Solar PV System" IEEE Trans. Power electronics, vol. 29, no. 10, october 2014.

[4] Bhim Singh, Fellow, IEEE, S. S. Murthy, Life Fellow, IEEE, and Raja Sekhara Reddy Chilipi "STATCOM-Based Controller for a ThreePhase SEIG Feeding Single-Phase Loads" IEEE Trans. Energy conversion, vol. 29, no. 2, june 2014.

[5] Sachi Sharma, "Single Phase d-q Transformation using as indirect Control Method for Shunt Active Power Filter" International Journal of Engineering Research and General Science Volume 2, Issue 3, April-May 2014.

[6] John S. Hsu, "Instantaneous Phasor Method for Obtaining Instantaneous Balanced Fundamental Components for Power Quality Control and Continuous Diagnostics" IEEE Trans. Power Delivery, vol.13, no.4, Oct 1998 . 